Article

\title{
Preparation of Macroporous PEK-C Powders with Chemically Linked Ionic Liquids as Catalyst and Kinetics Study of Biomass
}

\author{
Peng Lu*, Yong Cao and Xiaolan Wang \\ School of Chemistry and Chemical Engineering, Beijing Institute of Technology, Beijing 102488, China; \\ ycaobit@163.com (Y.C.); 294030700@bit.edu.cn (X.W.) \\ * Correspondence: penglu@bit.edu.cn; Tel.: +86-010-62750371
}

Received: 16 March 2018; Accepted: 19 April 2018; Published: 11 May 2018

\begin{abstract}
Macroporous cardo polyetherketone (PEK-C) powder catalyst bearing covalently ionic liquids (PEK-C-ILs) was prepared, it exhibited a high catalytic performance for biomass hydrolysis. A hydrolysis mechanism of inulin over this new catalyst was proposed as well. The influences of degree of chloromethylation of PEK-C, catalyst dosage, reaction temperature, pore size of PEK-C-ILs and inulin concentration were investigated. A high conversion of inulin of $99.7 \%$ was obtained under the optimal reaction conditions. Meanwhile, the hydrolysis kinetics was studied under different conditions. The proposed kinetic model of inulin hydrolysis catalyzed by PEK-C-ILs was established and it successfully predicted the inulin hydrolysis in wider ranges of experimental conditions. The results demonstrated that the catalytic inulin hydrolysis performance of PEK-C-ILs is better than that of homogenous ILs due to that there was a high-density spatial distribution of active sites on the surface and inner pore wall of PEK-C after the ILs was immobilized. Furthermore, the stability including chemical structure and physical appearance and reusability tests showed that PEK-C-ILs catalyst could be effectively separated and recovered from hydrolysates and has excellent reusability. Importantly, using the PEK-C-ILs as catalyst makes the recycling of ILs simplified, efficient and the hydrolysis process more economical. At the same time, it avoided the potential hazards of homogenous ILs to the environment. Therefore, it is a kind of green catalyst with potential application prospect in many catalysis fields.
\end{abstract}

Keywords: cardo polyetherketone; ionic liquids; immobilization; macroporous powder catalyst; inulin hydrolysis

\section{Introduction}

The exhaustion of fossil fuel and long term uncontrolled exploitation result in the severe environmental consequences. Biomass energy, due to their renewable, zero carbon dioxide emissions and lower sulphur content, have been received much more attention as environmentally benign alternative energy [1]. The biopolymer inulin, as a kind of polydisperse polysaccharide, consists of fructosyl fructose units which linked by $\beta-2,1$-glycosidic bonds, is one of the most abundant biomasses in the world. It exists as the main component in many plants such as helianthus tuberosus (Jerusalem artichoke) and chicory, which are cold-, heat-resistant and easy to cultivate even in barren soil [2]. The hydrolysis of inulin mainly produced fructose and then directly converted to ethanol by fermentation, thus existing feasibility for converting energy crops which containing abundant inulin polysaccharide to fuel ethanol. In addition, conversion of biomasses, such as cellulose and Jerusalem artichoke, to useful platform chemicals is a vital aspect in the replacement of petroleum-based feedstocks with sustainable alternatives [3]. 
Conventionally, the hydrolysis was carried out using concentrated acid [4], diluted acid [5] or enzyme [6] as catalysts. However, several disadvantages of these catalysts made this process inefficient and uneconomical. Inorganic acids could cause the problems of equipment corrosion, severe environmental pollution and generally expensive for commercial use [7]. As for enzyme, it is difficult to recycle and low efficiency as a result of the toxic side effects of the microorganism [8]. Thus, developing environmental friendly catalysts with wide industrial application for producing fermentable sugar from biomass is an urgent task.

Ionic liquids (ILs), as eco-friendly reaction media [9] and catalysts [10], have attracted increasing attention on account of the particular properties such as low volatility, non-inflammability, high thermal stability and prominent solubility. Moreover, the properties of ILs varied by altering the intercombination of cation and anion which make them more applicable in many physical and chemical fields. The functionalized ILs has been used in innumerous types of reactions and aroused great interest in recent years [11]. Studies involved the utilization of the functionalized ILs as catalysts for the hydrolysis of biomass have also been reported [12]. Zhao et al. [13] developed the hydrolysis kinetics models that predicted the inulin hydrolysis progress catalyzed by the homogeneous imidazole-based acidic ILs very well. Homogeneous functionalized ILs catalysts catalyzed effectively biomass hydrolysis process, but it presents several drawbacks, such as difficult for catalyst separation and recycling and high cost [14]. Herein, developing an approved strategy to overcome these limitations is urgently demand.

Immobilization of the functionalized ILs not only possesses much higher catalytic efficiency, but facilitates the separation of reactants and catalyst as well. Many works have focused on immobilized ILs on different materials, such as inorganic material [15], polymers [16] and magnetic materials [17]. Being cheap, separable and easily modified, polymeric materials are widely used to substitute others in many research fields. Xu et al. [18] suggested that the polystyrene-supported ILs ([SO $\left.{ }_{3} \mathrm{H}-\mathrm{PIM}\right]\left[\mathrm{HSO}_{4}\right]$ ) could effectively catalyze the esterifications and exhibit high catalytic activity. Additionally, the $\mathrm{CO}_{2}$ cycloaddition could be catalyzed using polymer-supported ILs catalyst and reached the high yield of $80-99 \%$, more importantly, excellent selectivity of $92-99 \%$ of cyclic carbonates could be achieved at mild conditions [19]. These outstanding performances suggested that the polymer immobilized ILs has potential applications in many fields.

Cardo polyetherketone (PEK-C) is a thermally stable polymer (Tg up to $230{ }^{\circ} \mathrm{C}$ ) with high mechanical properties due to the presence of cardo group on the main chains. PEK-C possess the excellent solubility in organic solvent such as 1,2-dichloroethane (DCA), dimethylformamide (DMF) and $N$-methylpyrrolidone (NMP), which makes it easy for membrane fabrication via non-solvent induced phase separation (NIPS) [19]. Previous studies have shown that PEK-C plays important parts in the development of membrane application and shows a good performance in the field of gas separation [20] and fuel cell [21]. For example, Hu et al. [21] applied the PEK-C powders as materials to prepare anion exchange membrane and presented satisfactory anion conductivity of $7.7 \mathrm{~ms} \mathrm{~cm}^{-1}$ at $20{ }^{\circ} \mathrm{C}$ in deionized water.

Nevertheless, there were few studies about the preparation of acidic ILs modified PEK-C material as catalyst and its application for hydrolysis of inulin. Therefore, the objective of this study was to seek a feasible approach of immobilizing ILs on the PEK-C material, then employ the IL-immobilized PEK-C (PEK-C-ILs) to prepare porous powders as a catalyst, and study the catalytic performance of PEK-C-ILs catalyst combining with hydrolysis mechanism discussion for hydrolysis of inulin into fermentable sugars for the production of ethanol. As well as this, the reusability of PEK-C-ILs catalyst was also investigated. 


\section{Experimental}

\subsection{Materials}

PEK-C was purchased from the Xuzhou Engineering Plastic Factory (Xuzhou, China). The number-average molecular weight $\left(\overline{M_{n}}\right)$ of PEK-C was 20,000. Inulin (polysaccharide: $93.2 \%$, initial reducing sugar: 3\%, moisture and ash: 3.8\%) was purchased from Gansu Likang Nutrition Food Corporation (Lanzhou, China); Chloromethyloctylether (CMOE) was synthesized in our lab according to the method described in literature [22]. Imidazole, 1,4-butylesultone and zinc chloride were purchased from Aladdin Chemical Company (Beijing, China); Diethyl ether and other chemicals (AR grade, purity 99.8 vol. \%) were commercially available and used without further purification.

\subsection{Preparation of ILs Modified PEK-C Powder (PEK-C-ILs) Catalyst}

The preparation of ILs modified PEK-C powder (PEK-C-ILs) catalyst was conducted in three steps, including chloromethylation of cardo polyetherketone (CMPEK-C), covalent immobilization of ILs, and powder formation. The preparation route was showed in Figure 1. The preparation process was described in detail in the Supplemental Material (showed in Section 2.2.1).

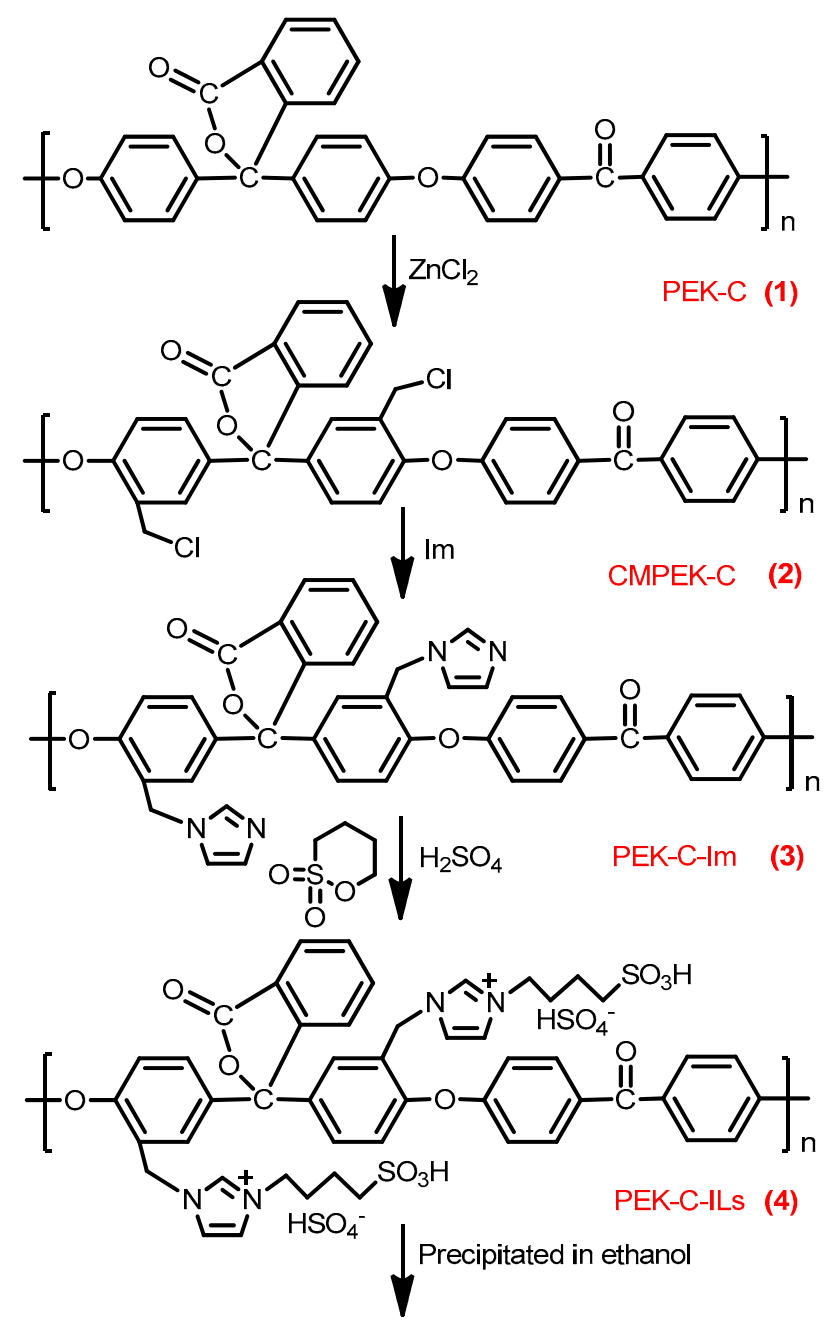

PEK-C-ILs Powder

(5)

Figure 1. Schematic for the fabrication of powdery PEK-C-ILs. 
The PEK-C-ILs powder was characterized by flourier transform infrared (FT-IR) (RX/BX-10, Nicolet, Boston, MA, USA) spectroscopy, nuclear magnetic resonance (NMR), X-ray photoelectron spectroscopy (XPS) analyzer (PHI-5300 ESCA, Perkin, Los Angeles, CA, USA), thermogravimetry analyzer (STA 449F3, Netzsch, Berlin, Germany) and field emission scanning electron microscopy (SEM) (JSM7401, LEI, Tokyo, Japan), respectively. The detailed results were presented in the Supplemental Material (showed in Sections 2.2.2.1-2.2.2.6).

In addition, the particle size of the most PEK-C-ILs powder catalysts was in the range of 140-170 $\mu \mathrm{m}$ which was tested using imageJ software analysis method (see the Supplemental Material, Figure S7).

\subsection{Hydrolysis of Inulin and Total Reducing Sugar (TRS) Assay}

In order to study the effects of reaction conditions on inulin hydrolysis, a series of experimental parameters were investigated. Firstly, the different concentration of the inulin aqueous solutions (\%, the weight ratio of the inulin to water) were prepared and heated to the required temperature in a $50 \mathrm{~mL}$ round bottom flask. And then a certain amount of PEK-C-ILs powder with needed concentration (wt \%, the weight ratio of the PEK-C-ILs to water and PEK-C-ILs; mol \%, the molar ratio of the ILs to inulin) subsequently added.

Along with the reaction time increased, $15 \mu \mathrm{L}$ of the clear solution from the hydrolyzate was transferred to a vial every $5 \mathrm{~min}$, while $1 \mathrm{~mL}$ of chromogenic agent (3,5-dinitrosalicylic acid, DNS) and $3 \mathrm{~mL}$ of deionized water were added. Then, the resulting solution was heated for $5 \mathrm{~min}$ in boiling water and $6 \mathrm{~mL}$ deionized water was added after cooled in the ice water bath. The principle of determination is that DNS is reduced to a brown red amino compound (3-amino-5-nitrosalicylic acid) after heating with reducing sugar hydrolyzed by polysaccharides under neutral or alkaline conditions. Finally, the absorbance was measured at $540 \mathrm{~nm}$ using UV-Vis double beam spectrophotometer (UV4802, Unico, Los Angeles, CA, USA). Reducing sugar concentration in the solution was calculated by employing a standard curve prepared using glucose. TRS can be calculated by the following equation:

$$
\text { TRS }=\frac{\text { Produced mass of reducing sugar }}{\text { Total mass of reducing sugar in the inulin }} \times 100 \%
$$

\subsection{Evaluation of the Catalyst Performance}

Turnover frequency (TOF) is defined as the conversion of reaction substrates by per mole of catalyst in unit time, which is an important index to evaluate the catalytic performance of catalysts. Turnover number (TON) is defined as the number of products generated by each active site of catalyst in unit time. They can be calculated by the following equation:

$$
\begin{gathered}
\text { TON }=\frac{\text { Molar quantity of product }}{\text { Molar quantity of catalyst }} \\
\text { TOF }=\frac{\text { TON }}{\text { Reaction time }}
\end{gathered}
$$

\subsection{Hydrolysis Kinetics Analysis}

The proposed kinetic model of inulin hydrolysis catalyzed by homogeneous ILs was established and it successfully predicted the inulin hydrolysis in wider ranges of experimental conditions [13]. In this work, the hydrolysis kinetics of PEK-C-ILs powder catalyst was also studied in inulin hydrolysis system. Due to the catalytic mechanism of inulin hydrolysis by PEK-C-ILs is consistent with that by the homogeneous ILs, the proposed kinetic model may also be employed to describe the inulin hydrolysis by the former. The hydrolysis kinetics followed the typical first order model with hydrolysis reaction [23]. Hydrolysis ratio $(R)$ can be obtained in the following equation,

$$
R=\frac{C_{R}}{C_{\max }}=1-\exp (-k t)
$$


where $C_{R}$ is the reducing sugars concentration, and $C_{\max }$ is the final reducing sugars concentration when inulin is hydrolyzed completely ( $\mathrm{mol} / \mathrm{L})$.

The kinetic constant $k$ is a function of absolute temperature according to the Arrhenius expression as follows

$$
k=A \exp \left(-\frac{E_{\mathrm{a}}}{R T}\right), \quad A=A_{0} C_{\mathrm{IL}}^{\mathrm{m}}
$$

where $E_{\mathrm{a}}$ is the activation energy $(\mathrm{kJ} / \mathrm{mol}), R$ is the molar gas constant $\left(8.314 \times 10^{-3} \mathrm{~kJ} / \mathrm{mol} \mathrm{K}\right), T$ is the temperature $(\mathrm{K}), A$ is the pre-exponential factor $\left(\mathrm{min}^{-1}\right)$ and was expressed by the corresponding literature [24]. $A_{0}$ is the pre-exponential parameter for inulin hydrolysis $\left(\mathrm{min}^{-1}\right), \mathrm{m}$ is the ILs concentration exponent for the rate constant $k$. $C_{\mathrm{IL}}$ is the concentration of ILs $(w / w \%$, the weight ratio of ILs to water and PEK-C-ILs). $C_{\mathrm{IL}}=x \% \times y \times M_{\mathrm{IL}} \cdot x \%$ is the concentration of PEK-C-ILs powder catalyst $(w / w \%$, the weight ratio of PEK-C-ILs to water and PEK-C-ILs). $y$ is loading amount of ILs $\left(1.541 \times 10^{-3} \mathrm{~mol} / \mathrm{g}\right.$ PEK-C-ILs powder). $M_{\mathrm{IL}}$ is the relative molecular mass of the ILs $(316 \mathrm{~g} / \mathrm{mol})$. In addition, activated energy and pre-exponential factor are related to the concentration of catalyst $\left(C_{\mathrm{IL}}\right)$. Thus, $E_{\mathrm{a}}$ could be expressed as follows

$$
E_{\mathrm{a}}=a \exp \left(-\frac{C_{\mathrm{IL}}}{b}\right)+c
$$

where $a, b$ and $c$ are constants.

\subsection{Recycling Utilization and Stability of PEK-C-ILs Powder Catalyst}

Upon reaction completion, PEK-C-ILs powder catalysts were filtered off and then washed repeatedly with deionized water $(3 \times 50 \mathrm{~mL})$ to remove the adsorbed reducing sugar. Then, PEK-C-ILs powder was collected and dried in vacuum at $60^{\circ} \mathrm{C}$ for $24 \mathrm{~h}$. This recycled catalyst was reused for the hydrolysis of inulin and the hydrolyzate was analyzed using procedure 2.4.

\section{Results and Discussion}

\subsection{Determination of Degree of Chloromethylation (DCM)}

DCM of PEK-C, defined as the average number chlormethyl groups per repeat unit of PEK-C, was used to evaluate the immobilization amount of catalyst. The Step CMPEK-C (2) from PEK-C (1) in Figure 1, chloromethylation of PEK-C plays an important role in the subsequent ILs immobilization reaction. That is to say, the number of chloromethyl groups attached to the polymer could affect the immobilization probability of ILs and further the catalytic hydrolysis efficiency. In this study, the conditions of chloromethylation reaction are very harsh and not easily controllable. When lower PEK-C/CMOE molar ratio $(1: 4)$ and higher temperature $\left(50^{\circ} \mathrm{C}\right)$ were adopted, cross-linking occurred and a polymer gel generated. This is not conducive to subsequent immobilization reaction of ILs. First, the repeat-unit molecular weight of the CMPEK-C (2) based on its mass change relative to PEK-C was calculated, and then determined DCM from the above obtained molecular weight. The details for the calculation have been given in the experimental section. Table 1 lists the results between the DCM and reaction time. From the experimental results we can see that the DCM can be increased along with the reaction time. When dichloroethane was used as the solvent and anhydrous zinc chloride as the catalyst, the intermediate products (PEK-C-Cl) with different chloromethylated degree were prepared by controlling the amount of chloromethylation reagent within different reaction time, and the maximum DCM can reached 1.46 for $20 \mathrm{~h}$. Meanwhile, when concentrated sulfuric acid was used as the solvent and catalyst, the DCM was obviously increased and can reached 3.51 at $30^{\circ} \mathrm{C}$ for $20 \mathrm{~h}$ (shown in Table 1).

However, concentrated sulfuric acid as a strong proton acid would cause equipment corrosion in a certain degree and it needs strict reaction conditions, such as PEK-C/CMOE molar ratio, in the chloromethylation process. On the other hand, when volatile dichloroethane was used as solvent, it will 
not only easily pollute the air, but relatively high cost of production, because of the high solvent price, long reaction time and elevated temperature. Thus, all things considered, the reaction media with concentrated sulfuric acid as catalyst was proposed. In addition, in order to obtain the optimal DCM, the catalytic performances of catalysts with different DCM were systematically investigated and the experimental results were analyzed in the followed results and discussion section.

Table 1. Conditions of chloromethylation reaction.

\begin{tabular}{cccc}
\hline Entry & Reaction Time/h & Temperature/ ${ }^{\circ} \mathbf{C}$ & DCM \\
\hline Simple in $\mathrm{C}_{2} \mathrm{H}_{2} \mathrm{Cl}_{2}{ }^{\mathrm{a}}$ & & & \\
\hline 1 & 6 & 40 & 0.46 \\
2 & 10 & 40 & 0.61 \\
3 & 12 & 40 & 0.95 \\
4 & 14 & 40 & 1.10 \\
5 & 16 & 40 & 1.28 \\
6 & 20 & 40 & 1.42 \\
7 & 24 & 40 & 1.46 \\
8 & & 40 & 1.45 \\
\hline Simple in $\mathrm{H}_{2} \mathrm{SO}_{4}{ }^{\mathrm{b}}$ & 2 & & \\
1 & 4 & 10 & 1.67 \\
2 & 6 & 10 & 1.82 \\
3 & 10 & 10 & 2.33 \\
4 & 15 & 10 & 2.81 \\
5 & 6 & 10 & 3.15 \\
6 & 15 & 30 & 3.33 \\
7 & 20 & 30 & 3.48 \\
8 & 2 & 30 & 3.51 \\
9 & 0.5 & 40 & $\mathrm{Gel}$ \\
10 & 50 & $\mathrm{Gel}$ \\
\hline
\end{tabular}

a Polymer:3 g; Catalyst: $\mathrm{ZnCl}_{2} 0.2$ g. ${ }^{\text {b }}$ Polymer:3 g; Solvent and catalyst: $\mathrm{H}_{2} \mathrm{SO}_{4} 98 \%$.

\subsection{The Catalytic Activity of PEK-C-ILs Powders (5)}

\subsubsection{Comparison of Catalytic Activity of PEK-C-ILs Powders with Sulfuric Acid}

In order to investigate the catalytic property of PEK-C-ILs powders for inulin hydrolysis, the equimolar dilute sulfuric acid and ILs immobilized onto porous PEK-C-ILs powders as catalysts were tested and the results were shown in Figure 2. It is clear that the catalytic activity of PEK-C-ILs powders was better than that of dilute sulfuric acid. At the reaction time of $20 \mathrm{~min}$, the PEK-C-ILs got the inulin hydrolysis ratio of $92.5 \%$, significantly higher than the hydrolysis ratio of $72.1 \%$ that dilute sulfuric acid obtained. Finally, the TRS yield of PEK-C-ILs powders catalyst could reach $99.7 \%$ at $45 \mathrm{~min}$. However, the acidity value of PEK-C-ILs powders catalyst is higher than that of dilute sulfuric acid (presented in Supplemental Material). The reason for this obvious difference of catalytic activities would be attributed to the different hydrolysis mechanism. It was well known that the classical acid hydrolysis mechanism usually has two key steps, one is the dissociation of hydrogen ion of acid, another is the nucleophilic attack of the hydrogen ion for glycosidic bond [25]. However, the possible hydrolysis mechanism of inulin polysaccharide seems to be more complex. In order to further verify this issue, the detailed catalytic mechanism of PEK-C-ILs catalyst would be analyzed respectively as follows. 


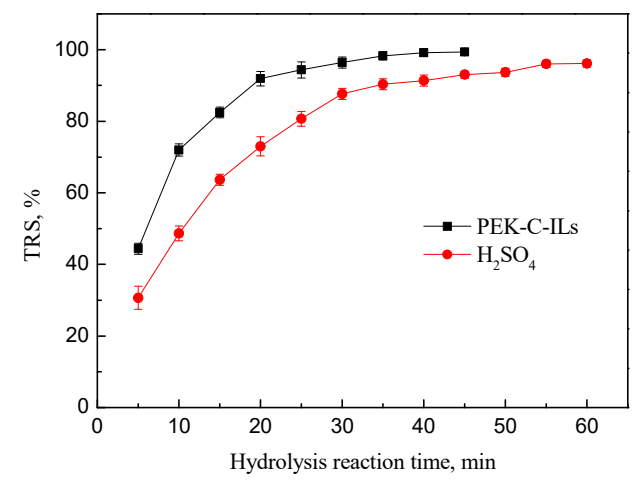

Figure 2. Catalytic performance of PEK-C-ILs powder and sulfuric acid. Hydrolysis condtions: inulin concentration $20 \%$, concentration of PEK-C-ILs $4.0 \mathrm{wt} \%$ (ILs $0.628 \mathrm{mmol}, 5.11 \mathrm{~mol} \%$ ), sulfuric acid $0.634 \mathrm{mmol}, \mathrm{DCM} 1.67$, temperature $65^{\circ} \mathrm{C}$.

\subsubsection{Hydrolysis Mechanism of PEK-C-ILs Catalyst}

Based on the previous study [26], two catalytic mechanism of inulin polysaccharide over PEK-C-ILs catalyst were proposed in this work and shown in Figure 3. As displayed in Figure 3a, when the glycosidic oxygen was being protonated by the acid catalyst, anion $\mathrm{HSO}_{4}{ }^{-}$as nucleophile was first attacked the anomeric carbon of the fructose molecule, leading to breaking of the glycosyl bond and the $-\mathrm{SO}_{3} \mathrm{H}$ groups of cation acts as proton donor for glycosidic oxygen. Then, the oxygen atom of a water molecule made a nucleophilic attack at the anomeric carbon concomitantly with deprotonation by the $-\mathrm{SO}_{3} \mathrm{H}$ group, completing the catalytic cycle of polysaccharide hydrolysis. The another path is synergistic hydrolysis process of cations. As displayed in Figure 3b, the oxygen atom of a water molecule was attacked by the deprotonation of the $-\mathrm{SO}_{3} \mathrm{H}$ groups in the cation. Then the glycosidic oxygen atom was being protonated under acidic condition, at the same time, the hydroxyl group of the water molecule attacked the anomeric carbon, resulting in cleavage of the glycosyl bond. The $-\mathrm{SO}_{3} \mathrm{H}$ groups in another cation acted as a proton acceptor for the other cyclic catalytic process. It should be noted that maybe there is a competitive relationship between them. And eventually the hydrolysis reaction was dominated by synergistic effect of anion and cation (Figure 3a) due to its low activation energy [27]. However, for sulfuric acid, its hydrolysis effect as a catalyst is poorer than PEK-C-ILs because the hydrolysis process only relied on the released hydrogen ion [25]. Therefore, this chemical and macroporous structures of PEK-C-ILs catalyst made it better hydrolysis active.

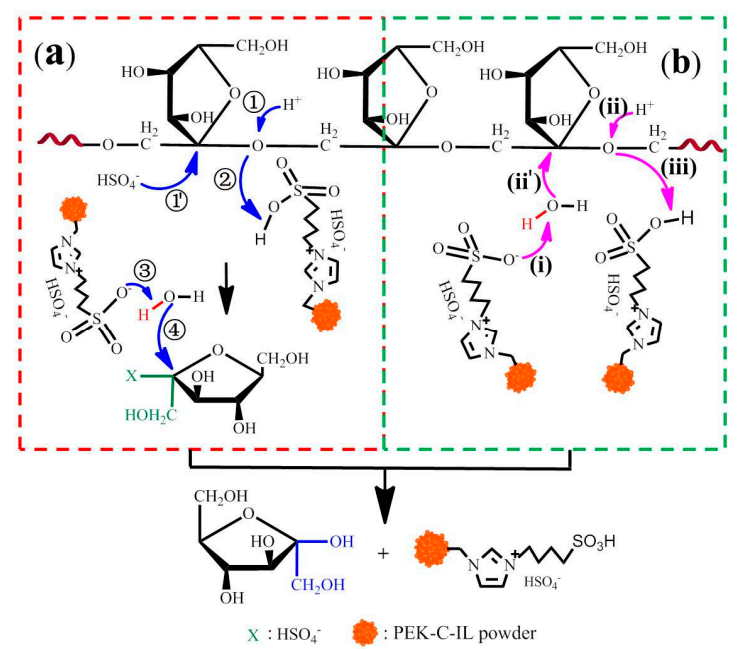

Figure 3. A plausible mechanism for the hydrolysis of inulin using PEK-C-ILs as catalyst. (a) synergistic effect of cations and anions (b) synergistic effect of cations. 


\subsection{Effect of Catalytic Conditions}

In the present study, the hydrolysis reaction was flexibly implemented with a round bottom flask. In order to obtain the appropriate reaction conditions of inulin hydrolysis for producing monosaccharide, DCM, catalyst dosage, reaction temperature, pore size of PEK-C-ILs powder and inulin concentration were investigated, respectively.

\subsubsection{Effect of Different DCM}

The first step of the study was designed to obtain the optimum DCM for high TRS yield of inulin hydrolysis using PEK-C-ILs as the catalyst. Figure 4 illustrates the effect of DCM variation on TRS. It is evident that the TRS increased with the increase of the DCM. The maximum TRS of $98.7 \%$ was obtained with 1.67 of DCM. However, with increase in DCM up to 1.82 , the TRS decreased to $81.3 \%$. This can be attributed to the molecules chain twine of ILs around each other, leading to the mutual coverage of active sites. Henceforth, it can be concluded that the DCM variation has a great effect on the TRS and the optimum DCM which obtained the maximum reducing sugar using the PEK-C-ILs catalyst is 1.67 .

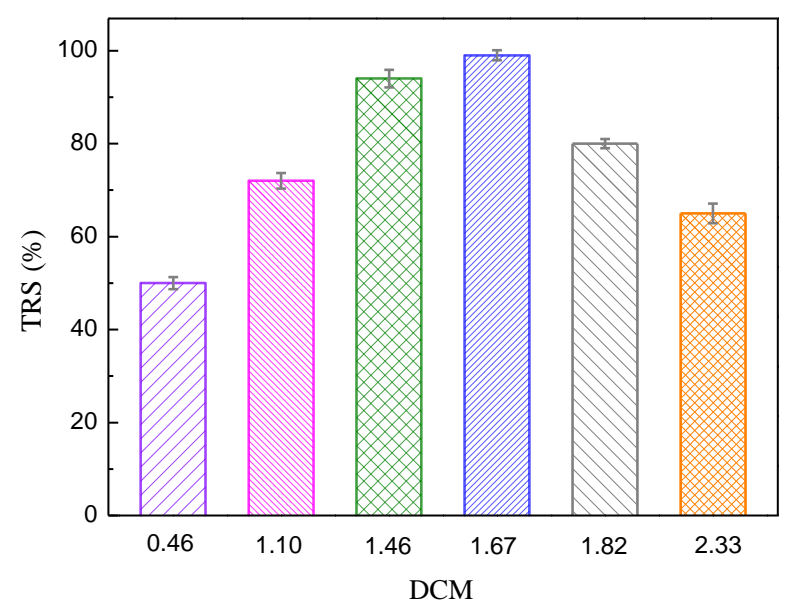

Figure 4. Effect of the DCM on the TRS of inulin. Hydrolysis conditions: inulin concentration $20 \%$, concentration of PEK-C-ILs 4 wt \%, temperature $65^{\circ} \mathrm{C}$.

\subsubsection{Effect of Catalyst Dosage}

The amount of PEK-C-ILs catalyst was varied in a range of 1.0-5.0 wt \% to carry out the hydrolysis reaction of inulin at $65^{\circ} \mathrm{C}$. The corresponding results were shown in Figure 5, we can see that the catalyst dosage has a profound effect on TRS of inulin. When the catalyst dosage increased from $1.0 \mathrm{wt} \%$ to $4.0 \mathrm{wt} \%(1.02-5.11 \mathrm{~mol} \%)$, the TRS increased obviously from $52.1 \%$ to $98.7 \%$. With further increase of the dosage, the TRS of inulin change slightly. This result may be due to the fact that the greater the catalyst dosage, the more available active sites for the hydrolysis reaction. However, when catalyst dosage was above $4.0 \mathrm{wt} \%$, the active sites were excess and could not been fully utilized for inulin hydrolysis, so that the hydrolysis rate of inulin had no significant increase. In addition, the comparison result between PEK-C-ILs powder catalyst of $4.0 \mathrm{wt} \%(0.628 \mathrm{mmol}$ ILs $)$ and homogeneous ILs clearly showed that the catalytic activity of ILs has been well improved after immobilization.

More importantly, we can evaluate the catalytic performance of catalyst by the TOF value in that the higher TOF value reflects the better catalytic property. The experimental results showed that the TOF of PEK-C-ILs is $6.767 \times 10^{-3} \mathrm{~s}^{-1}$, which is higher than homogeneous ILs of $4.873 \times 10^{-3} \mathrm{~s}^{-1}$. Therefore, the hydrolysis property of PEK-C-ILs powders was better than that of homogeneous ILs in the equimolar condition. Considering the catalytic activity and economical evaluation of the overall reaction process, the appropriate catalyst dosage is controlled in $4.0 \mathrm{wt} \%$. 


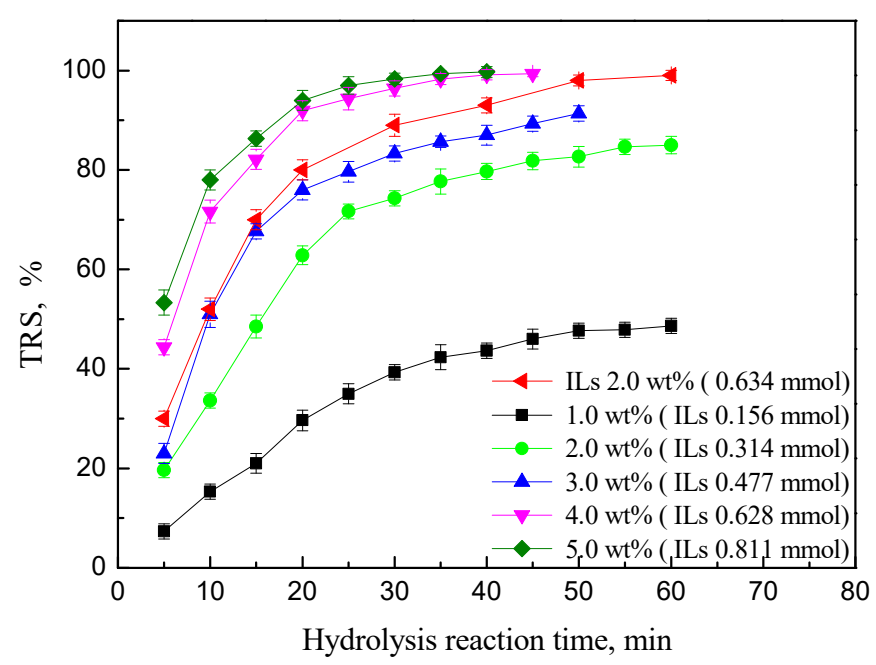

Figure 5. Effect of PEK-C-ILs dosage on the TRS of inulin. Hydrolysis conditions: inulin concentration $20 \%$, DCM 1.67, temperature $65{ }^{\circ} \mathrm{C}$. PEK-C-ILs concentration (wt \%, the weight ratio of the PEK-C-ILs to water and PEK-C-ILs).

In addition, the reasons why and how the macroporous PEK-C powder modified with an acidic ILs revealed high catalytic performance are mainly due to the reduced mass transfer resistance in pores and high-density spatial distribution of active sites on the powder. One hand, for the macroporous PEK-C powder, both the transfer resistance of inulin from outside into pore and the release resistance of the hydrolyzed fructose (reducing sugar) from pore into solution are small. On the other hand, the hydrolysis reaction was dominated by synergistic catalytic effect of anion and cation due to its low activation energy [27]. Because the PEK-C-ILs powder has a high-density spatial distribution of active sites on the surface and inner pore wall after the ILs was immobilized. Thus, the probability of synergistic action of ILs increased in the hydrolysis reaction, also resulting in the excellent catalytic performance of PEK-C-ILs powder catalyst.

\subsubsection{Effect of Temperature}

The reaction temperature is an important factor for the activity of catalysts in the most reaction systems. Therefore, hydrolysis of inulin with PEK-C-ILs catalyst was performed at different temperature in the range of $50-70{ }^{\circ} \mathrm{C}$ to find out the optimum temperature of hydrolysis reaction. The effects of the TRS of inulin at different temperature were exhibited in Figure 6. The results suggested that the increment of temperature is apparently favorable to accelerate the hydrolysis reaction. However, when reaction temperature was above $65^{\circ} \mathrm{C}$, the hydrolysis rate had no marked further change after $25 \mathrm{~min}$. At this moment, with the increase of temperature from $50{ }^{\circ} \mathrm{C}$ to $70{ }^{\circ} \mathrm{C}$, the corresponding TRS yields increased from $35.3 \%$ to $97.3 \%$.

Amarasekara et al. [15] prepared a sulfonic acid functionalized ILs modified silica as catalyst for cellulose hydrolysis. Using 1-n-butyl-3-methylimidazolium chloride as solvent, a maximum TRS yield of $67 \%$ was obtained when $10 \mathrm{~mol} \%$ catalyst was employed at $70{ }^{\circ} \mathrm{C}$ for $360 \mathrm{~min}$. Meanwhile, $\mathrm{Xu}$ et al. [28] investigated the hydrolysis of microcrystalline cellulose by ILs (3-sulfobutyl-1-(3-propyltriethoxy-silane) imidazolium hydrogen sulfate) supported silica and TRS reached $77 \%$ at $110{ }^{\circ} \mathrm{C}$ for $120 \mathrm{~min}$. These catalytic processes require an elevated temperature or a longer reaction time. Herein, from the view of energy conservation and economy, it is advisable that the reaction temperature of inulin hydrolysis system should not be fixed at a higher temperature due to reducing sugars are easy to further degrade. Hence, the hydrolysis temperature at $65{ }^{\circ} \mathrm{C}$ was recommended. 


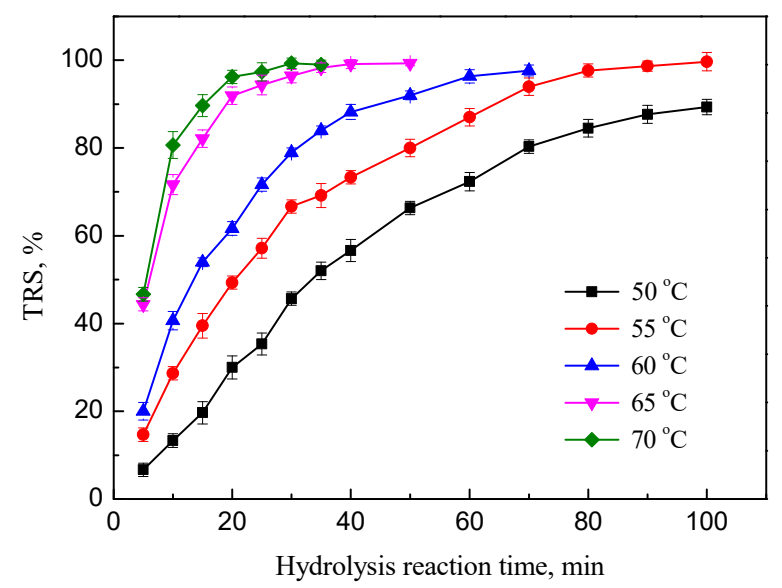

Figure 6. Effect of reaction temperature on the TRS of inulin. Hydrolysis conditions: inulin concentration 20\%, DCM 1.67. PEK-C-ILs concentration (wt \%, the weight ratio of the PEK-C-ILs to water and PEK-C-ILs).

\subsubsection{Effect of Pore Size}

Pore size was also an important parameter for the powder catalyst. The PEK-C-ILs powder catalysts with different pore size were prepared by adjusting the polymer concentration in $4 \mathrm{wt} \%$, $6 \mathrm{wt} \%$ and $8 \mathrm{wt} \%$, respectively. Using ImageJ software [29], the pore size of the PEK-C-ILs powders was analyzed base on the SEM images of Figure 7. Because the surface flateness of powder is low, it is difficult for the image analysis software to capture the macropore information. We prepared plate PEK-C-ILs films in the same preparation conditions as powders so as to test the pore size. The analysis results were listed in Table 2. It is illustrated that the decrease of surface pore size of PEK-C-ILs powder followed by the increase of polymer concentration.

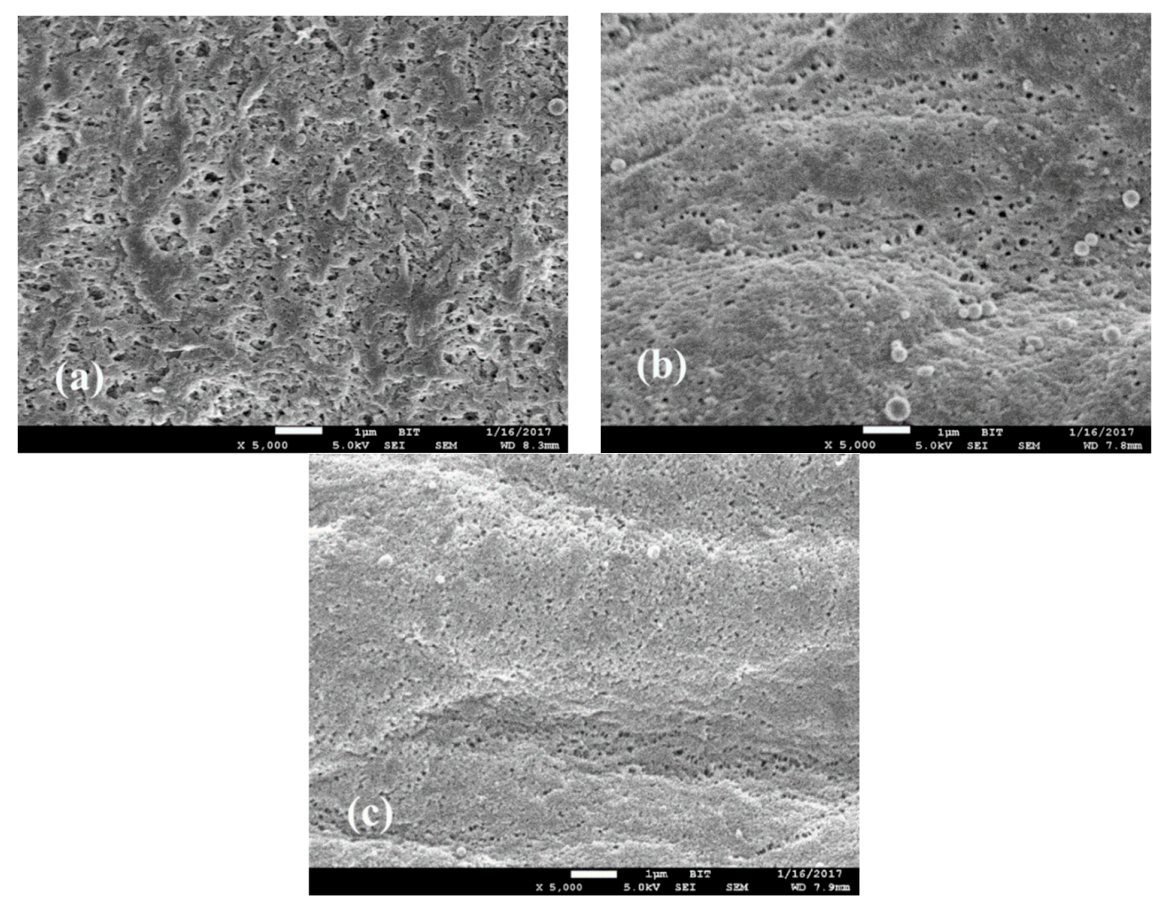

Figure 7. SEM images of the PEK-C-ILs powder surface. PEK-C-ILs concentration (a) 4 wt \%, (b) 6 wt \%, (c) $8 \mathrm{wt} \%$. 
Table 2. Pore size of PEK-C-ILs powder catalysts.

\begin{tabular}{cccc}
\hline PEK-C-ILs & A & b & c \\
\hline Mean pore size $/ \mathrm{nm}^{\text {a }}$ & 185 & 112 & 71 \\
\hline were measured using the imageJ software based on the SEM images of Figure 7.
\end{tabular}

Figure 8 depicted the variation of the TRS with an increase in pore size of PEK-C-ILs catalyst. These three kinds of powder catalyst with different pore size exhibited remarkable hydrolysis performance with yields up to $99 \%$. But they showed obvious different in both hydrolysis rate in first $2 / 3$ process and complete hydrolysis time. When reaction time was $25 \mathrm{~min}$, with the increase of mean pore size from $71 \mathrm{~nm}$ to $185 \mathrm{~nm}$, the corresponding TRS yields of inulin catalyzed by PEK-C-ILs powders increased from $90.1 \%$ to $96.3 \%$. When the pore size of powder catalyst was too small, the molecule transfer resistance in the internal pores increased. Then, the interaction possibility between the active sites of ILs immobilized on the pore wall and the glycosidic bonds decreased, resulting in lower hydrolysis efficiency.

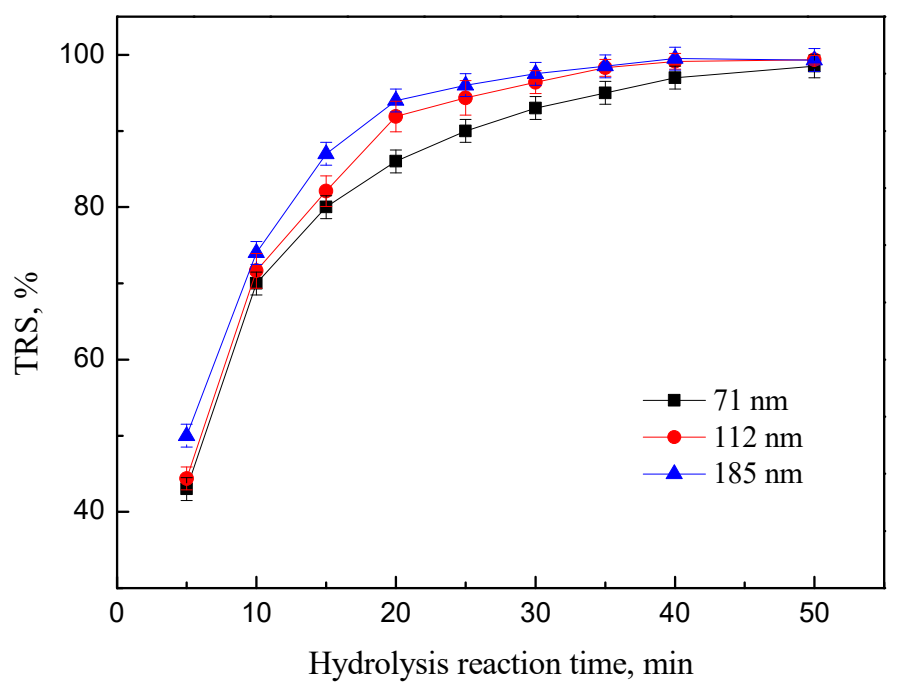

Figure 8. Effect of the pore size of the PEK-C-ILs powder catalyst on the TRS of inulin. Hydrolysis conditions: DCM 1.67, inulin concentration 20\%,PEK-C-ILs $4 \mathrm{wt} \%$,temperature $65^{\circ} \mathrm{C}$.

It is worth mentioning that the PEK-C-ILs powder catalyst with average pore size of $112 \mathrm{~nm}$ was used in the hydrolysis experiments of this work, which is obviously larger than the pore size of typical microporous silica materials with $2-5 \mathrm{~nm}$ [30]. Therefore, this macroporous powder catalyst perhaps exhibit more efficient catalytic performance in the field of high polymerization degree materials, such as cellulose, due to taking full advantage of the active sites of ILs immobilized on the pore wall.

\subsubsection{Effect of Inulin Concentration}

The effect of the inulin concentration on the hydrolysis reaction was studied experimentally. The hydrolysis results were presented in Figure 9. As shown in Figure 9a, when the amount of inulin concentration increased from $10 \%$ to $40 \%$, the growth of hydrolysis ratio was slowed down and it took a longer time for complete hydrolysis of inulin. When the concentration of inulin was lower than $30 \%$, the inulin almost could be completely hydrolyzed in $35 \mathrm{~min}$. The PEK-C-ILs powders catalyst exhibited excellent hydrolysis performance with yields up to $90 \%$ under these three kinds of inulin concentration at $25 \mathrm{~min}$. However, when the inulin concentration was more than $30 \%$, the hydrolysis rate of inulin was obviously decreased. The TRS yield at $25 \mathrm{~min}$ was only $78.1 \%$. This result can be explained in 
terms of dissolution mechanism and diffusion mechanism. A higher inulin concentration strongly increases the molecule diffusion resistance, which is not conducive to the process of mass transfer. In addition, the solubility of inulin is about 6-35\% under different temperature [31], so the dissolution of inulin with concentration of $40 \%$ was reduced, resulting in the hydrolysis rate decreased.

On the other hand, as shown in Figure 9b, the concentration of reducing sugar increased as the concentration of inulin increased from $10 \%$ to $40 \%$. The corresponding reducing sugar concentration was improved from $0.53 \mathrm{~mol} / \mathrm{L}$ to $1.82 \mathrm{~mol} / \mathrm{L}$. Compared to a solution with low concentration of inulin, increasing the inulin concentration caused an increase in density of glycosidic bonds, which enhanced the interaction probability between the active sites of ILs and the glycosidic bonds to a large extent. This behavior could result in a higher yield of reducing sugar. Thus, based on the above analysis, the hydrolysis rate increased with increasing the inulin concentration from $10 \%$ to $30 \%$, which improved the utilization efficiency of PEK-C-ILs powder catalyst. And considering economy, a higher initial inulin polysaccharide concentration is more favorable for fermentation solution, since it is desired to get higher ethanol concentration and then decrease the cost of ethanol/water separation in industry application, the appropriate concentration of inulin should be $30 \%$.
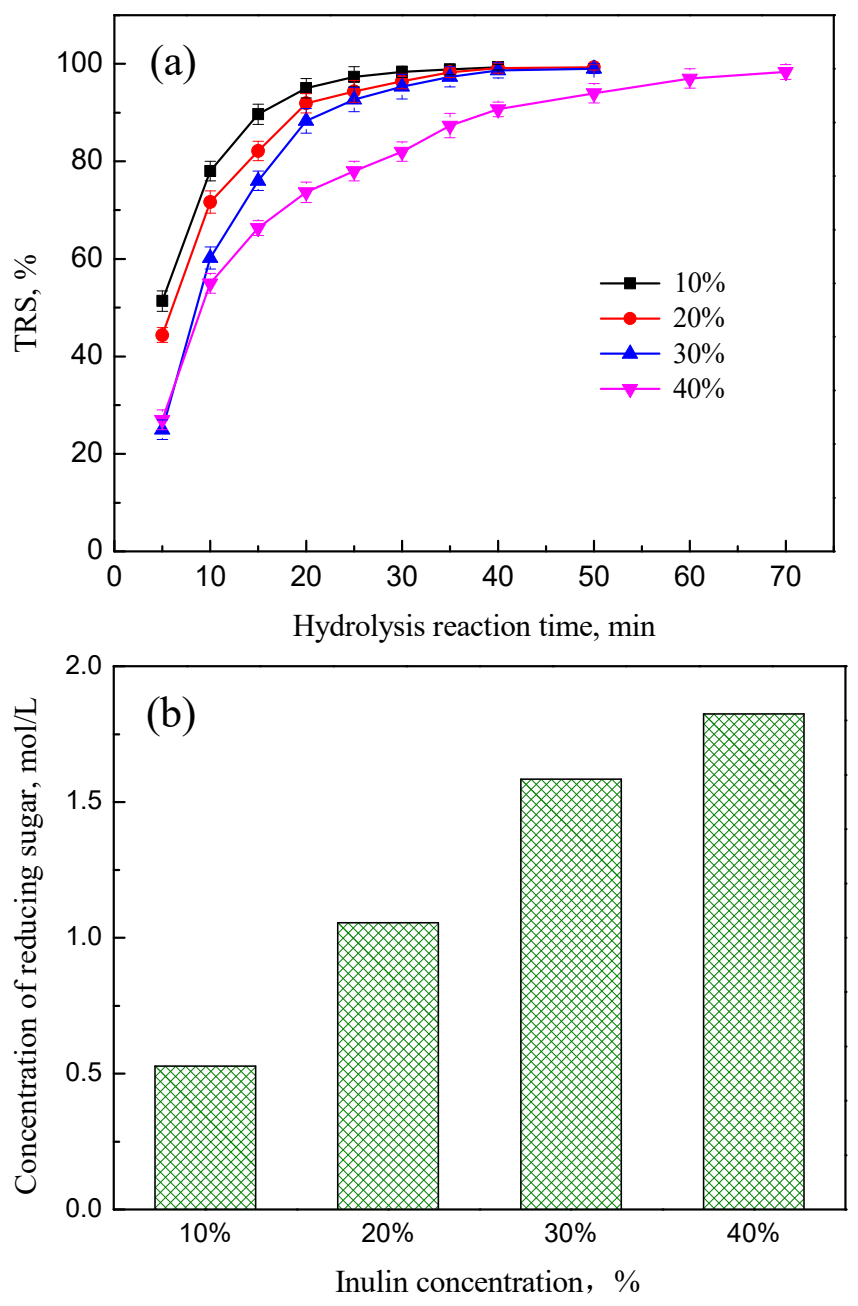

Figure 9. Effect of inulin concentration on the TRS. Hydrolysis conditions: concentration of PEK-C-ILs $4.0 \mathrm{wt} \%$, DCM 1.67, temperature $65^{\circ} \mathrm{C}$. (a) Variation tendency of TRS (b) Concentration of reducing sugar. 


\subsection{Hydrolysis Kinetics}

\subsubsection{Kinetic Parameters Estimation}

In order to further understand the hydrolysis behavior of inulin catalyzed by PEK-C-ILs, the kinetic parameters of hydrolysis kinetic model, such as reaction rate constant $(k)$, activation energy $\left(E_{\mathrm{a}}\right)$ and pre-exponential factor $(A)$, were obtained by estimating the experimental data. The relationship between the parameters was analyzed and the kinetic model was established to predict the inulin hydrolysis in wider ranges of experimental conditions. Table 3 shows the kinetic parameters for the hydrolysis of inulin polysaccharide. The activation energy decreased from $89.01 \mathrm{~kJ} / \mathrm{mol}$ to $82.80 \mathrm{~kJ} / \mathrm{mol}$ with increasing the PEK-C-ILs concentration from $1.0 \%$ to $5.0 \%$, while the pre-exponential factor in $\ln A$ increased from 27.39 to 27.89 . The changed activation energy indicates that there exists the different hydrolysis mechanism of PEK-C-ILs powder catalyst in the catalytic progress and the lower activation energy could be beneficial to the conduction of inulin hydrolysis. In the hydrolysis process, the synergistic effect of catalyst dominated gradually as the concentration of PEK-C-ILs increased, while the activation energy reduced. Furthermore, the pre-exponential factor is related to the number of effective active sites [32]. Thus, the lower catalyst concentration is not conducive to the hydrolysis reaction.

Table 3. The kinetics parameters of inulin hydrolysis by PEK-C-ILs powder catalysts.

\begin{tabular}{|c|c|c|c|c|c|c|c|c|}
\hline \multirow{2}{*}{$\begin{array}{c}\text { PEK-C-Ils } \\
\text { Concentration }(w / w \%)\end{array}$} & \multicolumn{5}{|c|}{$k\left(\min ^{-1}\right)$} & \multirow{2}{*}{$E_{\mathrm{a}}(\mathrm{kJ} / \mathrm{mol})$} & \multirow{2}{*}{$\ln A$} & \multirow{2}{*}{$R^{2}$} \\
\hline & $50^{\circ} \mathrm{C}$ & $55^{\circ} \mathrm{C}$ & $60^{\circ} \mathrm{C}$ & $65^{\circ} \mathrm{C}$ & $70^{\circ} \mathrm{C}$ & & & \\
\hline 1 & 0.00325 & 0.00541 & 0.00881 & 0.01410 & 0.02242 & 89.01 & 27.39 & 0.9967 \\
\hline 2 & 0.00678 & 0.01118 & 0.01809 & 0.02888 & 0.04551 & 87.59 & 27.58 & 0.9961 \\
\hline 3 & 0.02228 & 0.03610 & 0.05752 & 0.09035 & 0.14018 & 84.73 & 27.66 & 0.9923 \\
\hline 4 & 0.04286 & 0.06869 & 0.10863 & 0.16941 & 0.26065 & 83.21 & 27.80 & 0.9957 \\
\hline 5 & 0.05341 & 0.08551 & 0.13481 & 0.20972 & 0.32201 & 82.80 & 27.89 & 0.9925 \\
\hline
\end{tabular}

From the corresponding experimental results, the pre-exponential factor $A$ and $C_{\mathrm{IL}}$ (Equation (5)) could be stated as the following equation:

$$
k=A \exp \left(-\frac{E_{\mathrm{a}}}{R T}\right), A=3.88 \times 10^{12} C_{\mathrm{IL}}^{0.303}
$$

and the potential relationship (Equation (6)) between activation energy and $C_{\mathrm{IL}}$ may be further expressed as follows

$$
E_{\mathrm{a}}=13.34 \exp \left(-\frac{100 C_{\mathrm{IL}}}{1.02}\right)+81.49
$$

\subsubsection{Comparison of ILs, Dilute Sulfuric Acid and PEK-C-ILs Catalyst}

The kinetic parameters of inulin hydrolysis by PEK-C-ILs was calculated from the experimental results and the contrasting results of hydrolysis kinetics parameters by PEK-C-ILs, VImaILs and dilute sulfuric acid were listed in Table 4. All experiments were carried out in the equimolar ILs catalyst condition. It is noted that the hydrolysis rate constants by PEK-C-ILs were greater than by VImaILs and dilute sulfuric acid, which was attributed to the activation energy of PEK-C-ILs was smaller than that of latters. Furthermore, for PEK-C-ILs powder catalyst, the ILs immobilized on the surface and inner pore wall of PEK-C has a high-density spatial distribution. Thus, with the reaction temperature increased, the viscosity of inulin solution decreases and the effective collision probability between glycosidic bonds and active sites of ILs was strongly enhanced. However, the spatial distribution distance of equimolar homogenous ILs was greater than that of PEK-C-ILs powder catalyst. So in the homogenous ILs catalysis system, the probability of synergistic catalytic effect of cation and anion is decreased. It was concluded by simulation study that this synergistic effect could decreased 
the activation energy. Thus, this chemical and macroporous structures of PEK-C-ILs catalyst made it better hydrolysis active.

Table 4. Comparison of hydrolysis kinetics parameters by PEK-C-ILs, VImaILs and dilute sulfuric acid.

\begin{tabular}{cccccc}
\hline Catalyst & \multicolumn{2}{c}{$\boldsymbol{k}\left(\mathbf{m i n}^{-\mathbf{1}}\right)$} & \multirow{2}{*}{$\left.\boldsymbol{E}_{\mathbf{a}} \mathbf{( k J} / \mathbf{m o l}\right)$} & \multirow{2}{*}{$\boldsymbol{A}$} & \multirow{2}{*}{$\boldsymbol{R}^{\mathbf{2}}$} \\
\cline { 2 - 3 } & $\mathbf{5 5 ^ { \circ } \mathbf { C }}$ & $\mathbf{6 5}{ }^{\circ} \mathbf{C}$ & & & \\
\hline PEK-C-ILs & 0.0687 & 0.1694 & 83.21 & 27.80 & 0.9957 \\
VImaILs [13] & 0.0327 & 0.0781 & 83.68 & 27.25 & 0.9989 \\
Dilute sulfuric acid & 0.0173 & 0.0621 & 95.12 & 30.90 & 0.9802 \\
\hline
\end{tabular}

\subsubsection{Model Validation}

To validate the kinetic model, its predictive catalytic performance was tested with a group of experimental data. Figure 10 demonstrates that the theoretical calculation results were in very good accordance with the experimental results and the relative error was less than $3.0 \%$. It is clear that all the experimental data fit reasonably well with the kinetic values under different inulin concentration. Meanwhile, as shown in Figure 10d, it can be observed that the average variance has a tendency to increase with the increase of reaction time under the higher inulin concentration. It is mainly because of the increased mass transfer resistance of diffusion, which is reflected in two aspects: (i) the transfer resistance of inulin from outside into pore, (ii) the release resistance of the hydrolyzed fructose from pore into solution. However, the corresponding average variances were only $7.7 \%$. Therefore, we can conclude that the kinetic model can be used to predict the performance of the PEK-C-ILs catalyst.
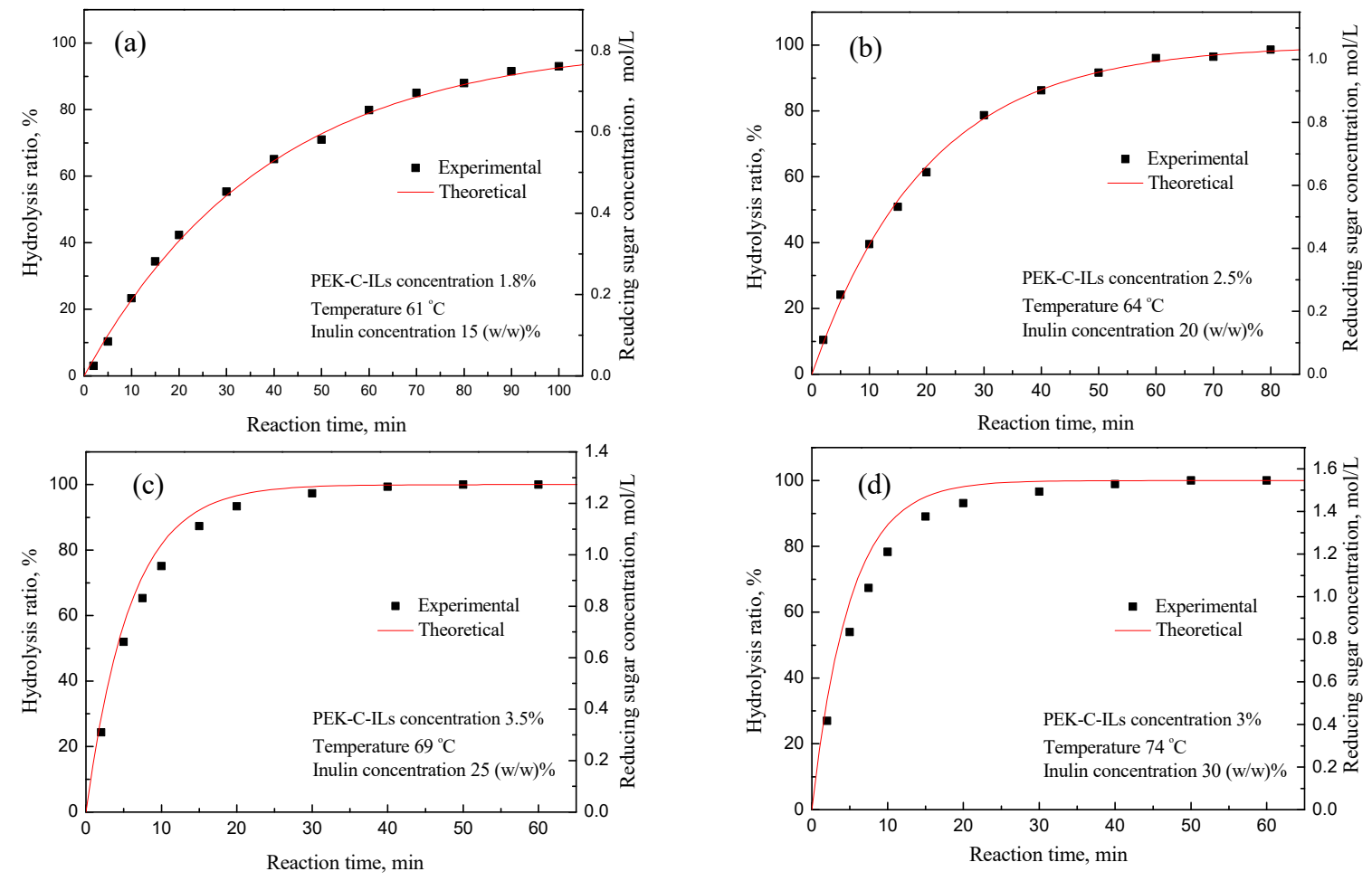

Figure 10. Reducing sugars yield curve as a function of process time. Experimental conditions: (a) Catalyst concentration $1.8 \%$, temperature $61{ }^{\circ} \mathrm{C}$, inulin concentration $15(w / w) \%$; (b) Catalyst concentration $2.5 \%$, temperature $64^{\circ} \mathrm{C}$, inulin concentration $20(w / w) \%$; (c) Catalyst concentration $3.5 \%$, temperature $69{ }^{\circ} \mathrm{C}$, inulin concentration $25(w / w) \%$; (d) Catalyst concentration $3 \%$, temperature $74{ }^{\circ} \mathrm{C}$, inulin concentration $30(w / w) \%$. 
Response Surface Methodology (RSM) can be regarded as a collection of statistical and mathematical techniques useful for optimizing objective functions. Thus, in order to investigate the effects of two independent variables on the yield of reducing sugars, the RSM experimental design was carried out. The analysis results were shown in Figure 11. It could be seen that the relative rate of inulin hydrolysis is enhanced by increasing the temperature and catalyst concentration. Figure 11a shows the surface representation of inulin hydrolysis ratio at 4.0\% PEK-C-ILs concentration over the temperature range from $300.15 \mathrm{~K}$ to $348.15 \mathrm{~K}$ and reaction time from $0 \mathrm{~min}$ to $80 \mathrm{~min}$. And the relationship between measured inulin hydrolysis ratio, PEK-C-ILs concentration (1.0-5.0\%) and reaction time (0-80 $\mathrm{min})$ at temperature $338.15 \mathrm{~K}$ was shown in Figure $11 \mathrm{~b}$. Analyzing the reducing sugars yield response surface will provide the useful information about operational conditions and results and understand the property-condition relationship of PEK-C-ILs catalyst.

(a)

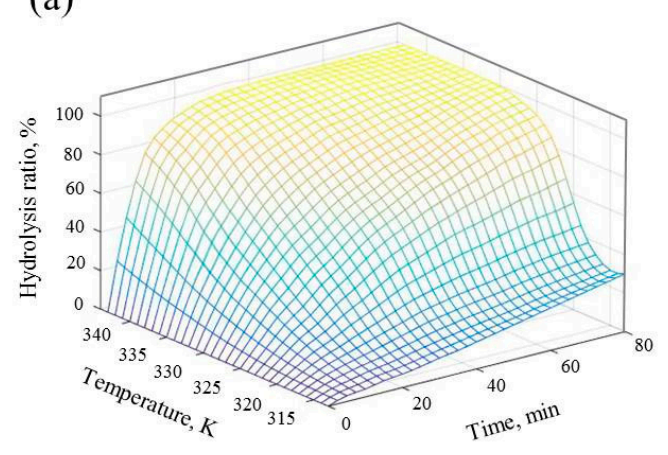

(b)

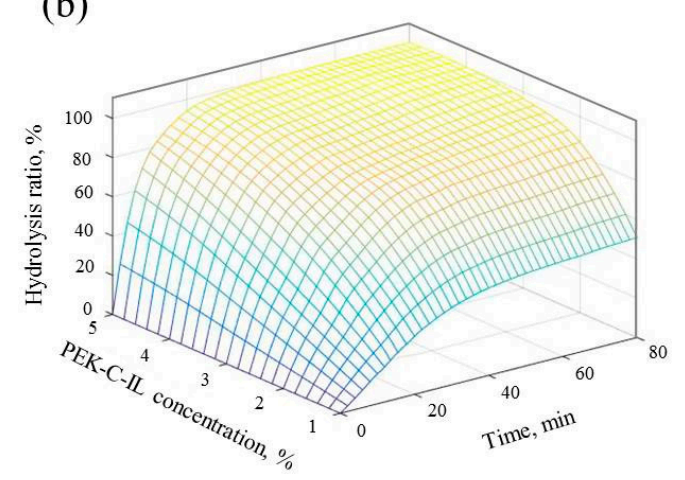

Figure 11. Reducing sugars yield surfaces as (a) a function of temperature and process time at $4.0 \%$ PEK-C-ILs concentration, (b) a function of PEK-C-ILs concentration and process time at $65^{\circ} \mathrm{C}$. Inulin concentration: $20(w / w) \%$.

\subsection{Stability and Reusability of Catalyst}

The reusage of catalyst is highly preferable for reducing cost of the production and potential environmental pollution. The PEK-C-ILs catalyst could be fully separated from hydrosate solution by filtration for recycling. After drying under vacuum at $50{ }^{\circ} \mathrm{C}$, it was subjected to the next new hydrolysis solutions. After used five times, the catalyst powder was washed with deionized water. Then it was used for next five rounds of hydrolysis experiment. The catalytic performance of the recycled PEK-C-ILs was shown in Figure 12. After the first and fifth rounds of hydrolysis, the TRS yields were $99.7 \%$ and $94.5 \%$, respectively. The results indicated that the catalyst could be reused five times with slightly decrease of $5.2 \%$ in catalytic activity. The reason for the decrease of the TRS seems to be primarily due to the active sites covered by reducing sugar in the catalysis process and a little shrinkage which resulted from oven dry after each hydrolysis. The recycled PEK-C-ILs powder after five rounds of use was washed with deionized water. After PEK-C-ILs powder dried, the hydrolysis reaction was conducted in the same conditions. Its catalytic activity recovered by $1.7 \%$. After the sixth and tenth rounds of hydrolysis, the TRS yields were $96.2 \%$ and $91.5 \%$, respectively. Compared with the original PEK-C-ILs powder catalyst, the PEK-C-ILs catalyst after 10 rounds hydrolysis showed only $8.2 \%$ loss of catalytic activity (Figure 12).

These results were consistent with the FT-IR and XPS analysis (showed in Supplemental Material). The FT-IR and XPS spectrum indicated that the PEK-C-ILs catalyst after 10 rounds was very stable and without obvious change in chemical structure after the catalysis operation. So, it was clearly that the ILs ( $\left.\left[\mathrm{SO}_{3} \mathrm{H}-\mathrm{PMIM}\right]\left[\mathrm{HSO}_{4}\right]\right)$ catalysts was firmly immobilized on the polymer PEK-C material. Therefore, it can be concluded that the PEK-C-ILs was efficient, stable and recyclable powder catalyst for the hydrolysis process of inulin. 


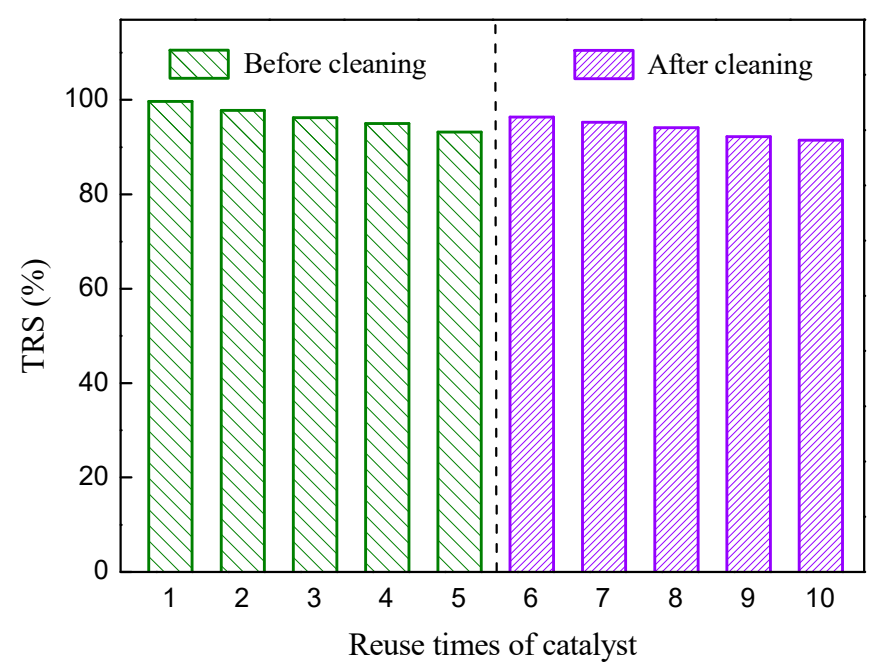

Figure 12. Recycling experiments of catalyst. Hydrolysis conditions: inulin concentration $20 \%$, concentration of PEK-C-ILs 4.0 wt \%, DCM 1.67, temperature $65^{\circ} \mathrm{C}$.

\section{Conclusions}

In this study, a macroporous cardo polyetherketone (PEK-C) powder covalently linked by functionalized acidic ILs as catalyst was prepared. It was then used for the hydrolysis of inulin polysaccharide, displaying excellent catalytic activity. A possible hydrolysis mechanism of inulin over this catalyst was proposed as well. Meanwhile, the hydrolysis kinetics was studied and the results demonstrated that the inulin hydrolysis rate by PEK-C-ILs was faster than the homogeneous ILs and dilute sulphuric acid due to there was a high-density spatial distribution of active sites on the surface and inner pore wall of PEK-C after the ILs was immobilized. So, the probability of synergistic catalytic effect of cation and anion of ILs was increased. And this proposed kinetic model successfully predicted the inulin hydrolysis in wider ranges of experimental conditions. Furthermore, this catalyst also showed high stability and reusability without significant loss of its catalytic performance. Therefore, it also avoided the potential hazards of homogenous ILs to the environment. From the perspective of hydrolysis efficiency and industrial economy, DCM of 1.67, powder catalyst dosage of $4.0 \mathrm{wt} \%$, reaction temperature of $65{ }^{\circ} \mathrm{C}$ and inulin concentration of $30 \%$ were experimentally selected as the optimum conditions for hydrolysis of inulin, and the maximum TRS yields was up to $99.7 \%$ in $40 \mathrm{~min}$. Meanwhile, the powder catalyst with larger macropore showed better catalytic performance due to reduced mass transfer resistance in the internal pores. The novel PEK-C-ILs powder catalyst opened up a wide avenue of biomass hydrolysis process toward bioethanol production and other platform chemicals.

Supplementary Materials: Supplementary materials can be found at http://www.mdpi.com/2076-3417/8/5/770/ s1.

Author Contributions: Y.C., P.L. and X.W. designed the experiments; P.L. performed the experiments; P.L. analyzed the data.

Conflicts of Interest: The authors declare no conflict of interest.

\section{References}

1. Baldwin, R.M.; Magrini-Bair, K.A.; Nimlos, M.R.; Pepiot, P.; Donohoe, B.S.; Hensley, J.E.; Phillips, S.D. Current research on thermochemical conversion of biomass at the National Renewable Energy Laboratory. Appl. Catal. B 2012, 115-116, 320-329. [CrossRef]

2. Shoaib, M.; Shehzad, A.; Omar, M.; Rakha, A.; Raza, H.; Sharif, H.R.; Shakeel, A.; Ansari, A.; Niazi, S. Inulin: Properties, health benefits and food applications. Carbohydr. Polym. 2016, 147, 444-454. [CrossRef] [PubMed] 
3. Czernik, S.; Bridgwater, A.V. Overview of Applications of Biomass Fast Pyrolysis Oil. Energy Fuels 2004, 18, 590-598. [CrossRef]

4. Iranmahboob, J.; Nadim, F.; Monemi, S. Optimizing acid-hydrolysis: A critical step for production of ethanol from mixed wood chips. Biomass Bioenergy 2002, 22, 401-404. [CrossRef]

5. Akpinar, O.; Erdogan, K.; Bostanci, S. Production of xylooligosaccharides by controlled acid hydrolysis of lignocellulosic materials. Carbohydr. Res. 2009, 344, 660-666. [CrossRef] [PubMed]

6. Yeh, A.I.; Huang, Y.C.; Chen, S.H. Effect of particle size on the rate of enzymatic hydrolysis of cellulose. Carbohydr. Polym. 2010, 79, 192-199. [CrossRef]

7. Hu, X.M.; Xiao, Y.B.; Niu, K.; Zhao, Y.; Zhang, B.X.; Hu, B.Z. Functional ionic liquids for hydrolysis of lignocellulose. Carbohydr. Polym. 2013, 97, 172-176. [CrossRef] [PubMed]

8. Zhao, H.; Jones, C.L.; Baker, G.A.; Xia, S.Q.; Olubajo, O.; Person, V.N. Regenerating cellulose from ionic liquids for an accelerated enzymatic hydrolysis. J. Biotechnol. 2009, 139, 47-54. [CrossRef] [PubMed]

9. Cole, A.C.; Jensen, J.L.; Ntai, L.; Tran, K.L.T.; Weaver, K.J.; Forbes, D.C.; Davis, J.H. Novel Brönsted acidic ionic liquids and their use as dual solvent-catalysts. J. Am. Chem. Soc. 2002, 124, 5962-5963. [CrossRef] [PubMed]

10. Zheng, W.Z.; Xie, W.X.; Sun, W.Z.; Zhao, L. Modeling of the interfacial behaviors for the isobutane alkylation with C4 olefin using ionic liquid as catalyst. Chem. Eng. Sci. 2017, 166, 42-52. [CrossRef]

11. Yu, G.R.; Zhao, J.J.; Song, D.D.; Asumana, C.; Zhang, X.Y.; Chen, X.C. Deep oxidative desulfurization of diesel fuels by acidic ionic liquids. Ind. Eng. Chem. Res. 2011, 50, 11690-11697. [CrossRef]

12. Tao, F.; Song, H.L.; Chou, L.J. Hydrolysis of cellulose in $\mathrm{SO}_{3} \mathrm{H}$-functionalized ionic liquid. Bioresour. Technol. 2011, 102, 9000-9006. [CrossRef] [PubMed]

13. Zhao, Z.P.; Wang, X.L.; Zhou, G.Y.; Cao, Y.; Lu, P.; Liu, W.F. Hydrolysis kinetics of inulin by imidazole-based acidic ionic liquid in aqueous media and bioethanol fermentation. Chem. Eng. Sci. 2016, 151, 16-24. [CrossRef]

14. Huddleston, J.G.; Visser, A.E.; Reichert, W.M.; Willauer, H.D.; Broker, G.A.; Rogers, R.D. Characterization and comparison of hydrophilic and hydrophobic room temperature ionic liquids incorporating the imidazolium cation. Green Chem. 2001, 3, 156-164. [CrossRef]

15. Amarasekara, A.S.; Owereh, O.S. Owereh, Synthesis of a sulfonic acid functionalized acidic ionic liquid modified silica catalyst and applications in the hydrolysis of cellulose. Catal. Commun. 2010, 11, 1072-1075. [CrossRef]

16. Yang, J.S.; Wang, J.; Liu, C.; Cao, L.P.; Xu, Y.X.; Che, Q.T.; He, R.H. Influences of the structure of imidazolium pendants on the properties of polysulfone-based high temperature proton conducting membranes. J. Membr. Sci. 2015, 493, 80-87. [CrossRef]

17. Chinnappan, A.; Bandal, H.; Kim, H.; Ramakrishna, S. Mn nanoparticles decorated on the ionic liquid functionalized multiwalled carbon nanotubes as a supercapacitor electrode material. Chem. Eng. J. 2017, 316, 928-935. [CrossRef]

18. Xu, Z.J.; Wan, H.; Miao, J.M.; Han, M.J.; Yang, C.; Guan, G.F. Reusable and efficient polystyrene-supported acidic ionic liquid catalyst for esterifications. J. Mol. Catal. A 2010, 332, 152-157. [CrossRef]

19. Sun, J.; Cheng, W.G.; Fan, W.; Wang, Y.H.; Meng, Z.Y.; Zhang, S.J. Reusable and efficient polymer-supported task-specific ionic liquid catalyst for cycloaddition of epoxide with $\mathrm{CO}_{2}$. Catal. Today 2009, 148, 361-367. [CrossRef]

20. Wang, Z.G.; Chen, T.L.; Xu, J.P. Gas transport properties of novel cardo poly(aryl ether ketone) with pendant alkyl group. Macromolecules 2000, 33, 5672-5679. [CrossRef]

21. Hu, J.; Zhang, C.X.; Zhang, X.D.; Chen, L.W.; Jiang, L.; Meng, Y.D.; Wang, X.K. A green approach for preparing anion exchange membrane based on cardo polyetherketone powders. J. Power Sources 2014, 272, 211-217. [CrossRef]

22. Warshawsky, A.; Deshe, A. Process for the Production of Halomethylating Agents which Are of Low Volatility. U.S. Patent US4568700A, 4 February 1986.

23. Barclay, T.; Ginic-Markovic, M.; Johnston, M.R.; Cooper, P.D.; Petrovsky, N. Analysis of the hydrolysis of inulin using real time ${ }^{1} \mathrm{H}$ NMR spectroscopy. Carbohydr. Res. 2012, 352, 117-125. [CrossRef] [PubMed]

24. Romero, I.; Ruiz, E.; Castro, E.; Moya, M. Acid hydrolysis of olive tree biomass. Chem. Eng. Res. Des. 2010, 88, 633-640. [CrossRef] 
25. Mamman, A.S.; Lee, J.M.; Kim, Y.C.; Hwang, I.T.; Park, N.J.; Hwang, Y.K.; Chang, J.S.; Hwang, J.S. Furfural: Hemicellulose/xylose derived biochemical. Biofuels Bioprod. Biorefin. 2008, 2, 438-454. [CrossRef]

26. Lu, P.; Zhao, Z.P.; Wang, X.Y.; Lan, G.J.; Wang, X.L. Understanding effect of molecular structure of imidazole-based ionic liquids on catalytic performance for biomass inulin hydrolysis. Mol. Catal. 2017, 435, 24-32. [CrossRef]

27. Li, J.J.; Li, J.H.; Zhang, D.J.; Liu, C.B. Theoretical explanation for how $\mathrm{SO}_{3} \mathrm{H}$-functionalized ionic liquids promote the conversion of cellulose to glucose. Chemphyschem 2015, 16, 3044-3048. [CrossRef] [PubMed]

28. Xu, H.M.; Zhao, H.H.; Song, H.L.; Miao, Z.C.; Yang, J.; Zhao, J.; Liang, N.; Chou, L.J. Functionalized ionic liquids supported on silica as mild and effective heterogeneous catalysts for dehydration of biomass to furan derivatives. J. Mol. Catal. A 2015, 410, 235-241. [CrossRef]

29. Sun, W.N.; Chen, T.; Chen, C.X.; Li, J.D. A study on membrane morphology by digital image processing. J. Membr. Sci. 2007, 305, 93-102. [CrossRef]

30. Escuin, P.C.; García-Bennett, A.; Ros-Lis, J.V.; Foix, A.A.; Andrés, A. Application of mesoporous silica materials for the immobilization of polyphenol oxidase. Food Chem. 2017, 217, 360-363. [CrossRef] [PubMed]

31. Ricca, E.; Calabro, V.; Curcio, S. The state of the art in the production of fructose from inulin enzymatic hydrolysis. Crit. Rev. Biotechnol. 2007, 27, 129-145. [CrossRef] [PubMed]

32. Yat, S.C.; Berger, A.; Shonnard, D.R. Kinetic characterization for dilute sulfuric acid hydrolysis of timber varieties and switchgrass. Bioresour. Technol. 2008, 99, 3855-3863. [CrossRef] [PubMed]

(C) 2018 by the authors. Licensee MDPI, Basel, Switzerland. This article is an open access article distributed under the terms and conditions of the Creative Commons Attribution (CC BY) license (http:/ / creativecommons.org/licenses/by/4.0/). 